\title{
Effect of complications on mortality after coronary artery bypass grafting surgery: Evidence from New York State
}

\author{
Laurent G. Glance, MD, ${ }^{a}$ Turner M. Osler, MD, FACS, ${ }^{b}$ Dana B. Mukamel, PhD, ${ }^{\mathrm{c}}$ and Andrew W. Dick, PhD ${ }^{\mathrm{d}}$
}

Earn CME credits at

http://cme.ctsnetjournals.org
From the University of Rochester School of Medicine, ${ }^{\text {a }}$ Rochester, NY; the University of Vermont Medical College, ${ }^{\mathrm{b}}$ Burlington, $\mathrm{Vt}$; the Center for Health Policy Research, ${ }^{\circ}$ University of California, Irvine, Calif; and RAND, ${ }^{\mathrm{d}}$ Pittsburgh, Pa.

The views presented in this manuscript are those of the authors and might not reflect those of Agency for Healthcare and Quality Research or of the New York State Department of Health or of the Cardiac Advisory Committee.

Supported by a grant from the Agency for Healthcare and Quality Research (RO1 HS 13617).

Received for publication Jan 2, 2007; accepted for publication Feb 12, 2007.

Address for reprints: Laurent G. Glance, MD, Department of Anesthesiology, University of Rochester Medical Center, 601 Elmwood Ave, Box 604, Rochester, NY 14642 (E-mail: Laurent_Glance@urmc. rochester.edu).

J Thorac Cardiovasc Surg 2007;134:53-8

$0022-5223 / \$ 32.00$

Copyright () 2007 by The American Association for Thoracic Surgery

doi:10.1016/j.jtcvs.2007.02.037
Objective: Complications are associated with increased risk of death. The objective of this study is to quantify the increased odds of dying from complications after isolated coronary artery bypass grafting surgery.

Methods: We conducted a retrospective cohort study using the New York State Coronary Artery Bypass Grafting Surgery Reporting System for all patients undergoing isolated coronary artery bypass grafting surgery in New York State who were discharged between 1997 and 1999 (51,750 patients; 2.20\% mortality). We estimated the independent effect of individual postoperative complications on in-hospital mortality after controlling for patient clinical risk factors and demographics.

Results: The mortality rate for patients without complication was $0.77 \%$ versus $16.1 \%$ for patients with complications $(P<.001)$. After adjusting for preoperative risk factors, transmural myocardial infarction (adjusted odds ratio, 7.90; $P<.001$ ), respiratory failure (adjusted odds ratio, 6.02; $P<.001$ ), renal failure (adjusted odds ratio, $7.15 ; P<.001$ ), and stroke within 24 hours (adjusted odds ratio, $4.09 ; P<$ $.001)$ were the most strongly associated with mortality.

Conclusions: There is a strong association between postoperative complications and in-hospital mortality. Complications after isolated coronary artery bypass grafting surgery are associated with a 1.4- to 8-fold increase in the odds of death after adjusting for severity of disease and comorbidities. This information might prove valuable to hospitals in their efforts to design quality improvement initiatives and care protocols to improve mortality after coronary artery bypass grafting surgery.

$\mathrm{C}$ oronary artery disease is the leading cause of death in the United States. ${ }^{1}$ Recent evidence suggests that coronary artery bypass grafting (CABG) surgery might be the treatment of choice in patients with multivessel coronary artery disease. ${ }^{2}$ The release of public and nonpublic CABG outcome report cards is associated with reductions in CABG mortality rates. ${ }^{3-5}$ Even greater reductions in mortality rates might be achievable if hospitals can identify which complications are associated with the highest mortality and then focus quality improvement efforts on these complications. ${ }^{6}$

The purpose of this study was to estimate the increased risk of mortality in patients who have specific complications after CABG surgery. Because higher-risk patients are both more likely to have complications and to die, it is important to adequately adjust for severity of disease to quantify the contribution of complications to mortality. ${ }^{7}$ Administrative data are not ideally suited to this type of analysis because they frequently undercode both complications ${ }^{8-11}$ and comorbidities ${ }^{12,13}$ and often do not accurately differentiate between complications and comorbidities. ${ }^{14,15}$ We chose to perform this analysis using the New York State (NYS) Coronary Artery Bypass Surgery Reporting System (CSRS) database, which contains clinical data on mortality, complications, and preoperative risk factors for all patients undergoing isolated CABG surgery in NYS. ${ }^{3}$ 


\section{Abbreviations and Acronyms}

ACC = American College of Cardiology

AHA $=$ American Heart Association

$\mathrm{CABG}=$ coronary artery bypass grafting

CSRS $=$ Coronary Artery Bypass Surgery Reporting System

NYS $=$ New York State

$\mathrm{OR} \quad=$ odds ratio

\section{Materials and Methods \\ Data}

This study uses data from the NYS CSRS and includes all patients undergoing isolated CABG surgery in NYS who were discharged between 1997 and 1999 (51,750 patients; 2.20\% mortality). This database includes information on patient demographics, hospital and physician identifiers (encrypted), preoperative risk factors, and outcomes. These clinical data were collected prospectively at the hospital level and were then submitted to the NYS Department of Health. Audit mechanisms were in place to ensure the accuracy of the data. ${ }^{16}$ This study was exempted from institutional review board approval because it involved the secondary use of pre-existing data.

Information on left ventricular function was missing for approximately $3 \%$ of the patients. ${ }^{*}$ We constructed an imputation model ${ }^{17}$ to predict the ejection fraction by using the STATA (STATA Corp, College Station, Tex) "impute" procedure, which is based on best-subset regression. Imputed values for patients with missing ejection fractions were calculated by using the imputation model.

Initial exploratory analyses compared the distribution of individual risk factors for patients without postoperative complications with those for patients with at least 1 complication. Continuous covariates were compared by using the $t$ test, and categoric covariates were compared by using the $\chi^{2}$ test.

\section{Model Development}

We first constructed a risk adjustment model to predict in-hospital mortality that included only preoperative risk factors. Bivariate analyses were performed to evaluate the association between mortality and patient preoperative risk factors. Those risk factors with a $P$ value of .20 or less were considered candidate variables for inclusion in the multivariate prediction model. Forward stepwise selection $(P \leq .05)$ was used to identify the risk factors that were independently associated with in-hospital mortality. The method of fractional polynomials ${ }^{18}$ was used to determine the optimal transformation for continuous covariates. Robust variance estimators ${ }^{19}$ were used to account for the fact that outcomes for patients treated by the same surgeon were likely to be correlated. We then estimated a second model, based on the first model, which also included postoperative complications, in addition to previously identified preoperative risk factors, as predictor variables for mortality. Model discrimination was evaluated by using the c-statistic. ${ }^{20}$ This final model was used to estimate the independent contribution of individual postoperative complications to in-hospital mortality.

*For the purpose of this analysis, we defined an ejection fraction of zero as missing data.
All statistical tests were 2-tailed. Data management, regression analysis, and regression diagnostics were performed with STATA SE/9.1 software (STATA Corp).

\section{Results}

The study sample consisted of 57,150 patients treated by 189 surgeons at 33 hospitals. The preoperative risk factors for death of the patient groups with and without complications are compared in Table 1. Compared with patients without complications, patients who went on to sustain 1 or more complications were more likely on presentation to be in congestive heart failure, to be unstable, to be in shock, to have undergone cardiopulmonary resuscitation, or to be transferred on an emergency basis to the operating room after an unsuccessful percutaneous intervention. They were also more likely to have significant comorbidities (diabetes, hepatic failure, renal failure, and chronic obstructive pulmonary disease) and to have more severe atherosclerotic disease (previous stroke, carotid disease, aortoiliac disease, femoral-popliteal disease, and calcified aorta). They were also more likely to have poor ventricular function (left ventricular ejection fraction $\leq 20 \%$ ) and to have had a recent myocardial infarction, previous cardiac surgery, and left main coronary artery disease.

Approximately $9 \%$ of the patients had 1 or more complications after isolated CABG surgery (Table 1). The mortality rate for patients with 1 or more complications $(16.1 \%)$ was 20 times the mortality of patients with no complications $(0.77 \%, P<.001)$. Complications that were associated with the highest mortality rates were renal failure $(49.4 \%)$, sepsis $(41.6 \%)$, gastrointestinal bleeding $(32.6 \%)$, and respiratory failure $(31.2 \%)$. After adjusting for preoperative risk factors, transmural myocardial infarction (adjusted odds ratio [OR], 7.90; $P<.001$ ), respiratory failure (adjusted OR, 6.02; $P<.001$ ), renal failure (adjusted OR, 7.15; $P<.001$ ), and stroke within 24 hours (adjusted OR, 4.09; $P<.001$ ) were most strongly associated with mortality (Table 2$)$. The full model is shown in Appendix 1.

\section{Discussion}

We find that patients undergoing isolated CABG surgery who have 1 or more complications during the postoperative period have between a 1.4- and 8-fold increase in the odds of mortality compared with patients who do not have complications during the postoperative period. This study is the first multicenter study to examine the effect of postoperative complications on in-hospital mortality after isolated CABG surgery. Through a better understanding of the effect of individual complications on mortality, hospitals might be able to more effectively focus their quality improvement effort on reducing those complications that have the greatest effect on mortality.

In theory, a focused approach that targets specific complications through the application of evidence-based clinical 
TABLE 1. Preoperative risk factors of patients with and without any postoperative complications

\begin{tabular}{|c|c|c|c|}
\hline & $\begin{array}{c}\text { No complications } \\
(n=51,789)\end{array}$ & $\begin{array}{l}\text { Any complication } \\
(n=5361)\end{array}$ & $P$ value \\
\hline \multicolumn{4}{|l|}{ Demographics } \\
\hline Age (y) & 65.7 & 68.9 & $<.001$ \\
\hline Female sex & 28.2 & 34.3 & $<.001$ \\
\hline $\operatorname{BSA}\left(\mathrm{m}^{2}\right)$ & 1.99 & 1.94 & $<.001$ \\
\hline \multicolumn{4}{|l|}{ Hemodynamic status } \\
\hline Unstable & 1.14 & 3.58 & $<.001$ \\
\hline Shock & 0.35 & 1.92 & $<.001$ \\
\hline CPR & 0.15 & 0.75 & $<.001$ \\
\hline Intravenous nitroglycerin within $24 \mathrm{~h}$ & 19.2 & 27.8 & $<.001$ \\
\hline CHF, this admission & 11.1 & 22.0 & $<.001$ \\
\hline CHF, previous admission & 7.60 & 11.2 & $<.001$ \\
\hline Malignant ventricular arrhythmia & 2.00 & 3.66 & $<.001$ \\
\hline Emergency transfer to $\mathrm{OR}$ after $\mathrm{PCl}$ & 0.69 & 2.70 & $<.001$ \\
\hline \multicolumn{4}{|l|}{ Comorbidities } \\
\hline Diabetes & 30.0 & 35.5 & $<.001$ \\
\hline Hepatic failure & 0.08 & 0.41 & $<.001$ \\
\hline Renal failure, not on dialysis & 1.10 & 2.33 & $<.001$ \\
\hline Renal failure, on dialysis & 1.54 & 4.68 & $<.001$ \\
\hline Chronic obstructive pulmonary disease & 15.4 & 21.2 & $<.001$ \\
\hline \multicolumn{4}{|l|}{ Severity of atherosclerotic disease } \\
\hline Previous stroke & 6.32 & 11.7 & $<.001$ \\
\hline Carotid disease & 13.6 & 21.9 & $<.001$ \\
\hline Aortoiliac disease & 4.64 & 8.64 & $<.001$ \\
\hline Femoral-popliteal disease & 8.42 & 14.1 & $<.001$ \\
\hline Calcified aorta & 5.40 & 11.6 & $<.001$ \\
\hline \multicolumn{4}{|l|}{ Ventricular function } \\
\hline Ejection fraction $\leq 20$ & 1.63 & 3.32 & $<.001$ \\
\hline Previous $\mathrm{Ml},<6 \mathrm{~h}$ & 0.73 & 2.35 & $<.001$ \\
\hline Previous MI, 6-23 h & 0.77 & 1.96 & $<.001$ \\
\hline Previous MI, 1-7 d & 14.2 & 15.15 & .052 \\
\hline Previous $\mathrm{MI},>7 \mathrm{~d}$ & 40.9 & 42.9 & .004 \\
\hline \multicolumn{4}{|l|}{ Previous cardiac surgery } \\
\hline 1 & 5.39 & 8.38 & $<.001$ \\
\hline$\geq 2$ & 0.44 & 0.65 & .027 \\
\hline \multicolumn{4}{|l|}{ Extent of coronary artery disease } \\
\hline Left main, 70\%-89\% & 8.92 & 10.2 & .002 \\
\hline Left main, $>89 \%$ & 5.57 & 7.78 & $<.001$ \\
\hline
\end{tabular}

All values are percentages unless otherwise stated. Continuous variables were compared by using 2-sample $t$ tests, and categoric variables were compared by using the $\chi^{2}$ test. $B S A$, Body surface area; $C P R$, cardiopulmonary resuscitation; $C H F$, congestive heart failure; $O R$, operating room; $P C I$, percutaneous coronary intervention; $M I$, myocardial infarction.

practice guidelines might have a significant effect on complication rates and mortality. Implementation of the American College of Cardiology (ACC)/American Heart Association (AHA) Practice Guidelines ${ }^{21}$ might help to reduce the incidence of complications and their associated mortality. Some of the practice guidelines issued by the ACC/AHA include (1) the administration of blood cardioplegia in patients undergoing urgent/emergency CABG surgery or in patients with severe left ventricular dysfunction to improve myocardial protection, (2) the prophylactic use of an intraaortic balloon pump in patients with severe left ventricular dysfunction as an adjunct to myocardial protection, (3) the preoperative administration of antibiotics to reduce the risk of surgical infection, and (4) the postoperative use of antiplatelet therapy and statin therapy to reduce the risk of saphenous vein graft closure. Of the 6 recommendations issued by the ACC/AHA, however, only 3 are class I recommendations ${ }^{\dagger}$ supported by strong evidence. ${ }^{*}$ The nar-

$\uparrow$ “Conditions for which there is evidence and/or general agreement that a given procedure or treatment is beneficial, useful, and effective."21

$\ddagger$ “Data derived from multiple randomized clinical trials or meta-analyses." ${ }^{21}$ 
TABLE 2. Association between mortality and complications before and after adjusting for preoperative clinical risk factors

\begin{tabular}{|c|c|c|c|c|c|c|}
\hline & \multirow[b]{2}{*}{ No. } & \multirow[b]{2}{*}{ Dead, \% } & \multicolumn{2}{|c|}{ Bivariate analysis } & \multicolumn{2}{|c|}{ Multivariate analysis } \\
\hline & & & Unadjusted OR & $P$ value & Adjusted OR & $P$ value \\
\hline \multicolumn{7}{|l|}{ Cardiac } \\
\hline \multicolumn{7}{|l|}{ Pulmonary } \\
\hline Respiratory failure & 2311 & 26.9 & 31.2 & $<.001$ & 6.02 & $<.001$ \\
\hline \multicolumn{7}{|l|}{ Renal } \\
\hline \multicolumn{7}{|l|}{ Neurological } \\
\hline Stroke, within $24 \mathrm{~h}$ & 502 & 19.9 & 11.9 & $<.001$ & 4.09 & $<.001$ \\
\hline Stroke, $>24 \mathrm{~h}$ & 642 & 17.3 & 10.1 & $<.001$ & 3.58 & $<.001$ \\
\hline \multicolumn{7}{|l|}{ Bleeding } \\
\hline Bleeding requiring reoperation & 1252 & 10.2 & 5.51 & $<.001$ & 2.60 & $<.001$ \\
\hline \multicolumn{7}{|l|}{ Gastrointestinal } \\
\hline
\end{tabular}

The multivariate logistic regression model is adjusted for the following covariates: age, sex, body surface area, hemodynamic status (unstable, shock, cardiopulmonary resuscitation, intravenous nitroglycerin within 24 hours, congestive heart failure on this admission, history of congestive heart failure on a previous admission, malignant ventricular arrhythmia, and emergency transfer to operating room after percutaneous intervention), comorbidities (diabetes, hepatic failure, renal failure not on dialysis, renal failure on dialysis, and chronic obstructive pulmonary disease), severity of atherosclerotic disease (previous stroke, carotid disease, aortoiliac disease, femoral-popliteal disease, and calcified aorta), ventricular function (ejection fraction and previous myocardial infarction), previous cardiac surgery, and extent of coronary artery disease. C-statistic $=0.917$. OR, Odds ratio; Gl, gastrointestinal.

row scope of these practice guidelines, however, highlights the critical limitations of the evidence base linking processes of care to outcomes after cardiac surgery and reinforces the need to further expand the list of evidence-based best practices.

Recent studies have estimated the effect of complications for Medicare patients undergoing general and orthopedic surgery $^{7}$ and for Veterans Administration patients undergoing major vascular, general, and orthopedic surgery. ${ }^{6}$ Using a case-control design, Silber and colleagues ${ }^{7}$ found that Medicare patients who experienced a postoperative complication had 3.4-fold increased risk of mortality within 60 days of admission compared with patients without a complication. Using data from the National Surgical Quality Improvement Program database, Khuri and associates ${ }^{6}$ found that Veterans Administration patients undergoing major noncardiac surgery who experienced a postoperative complication had their median survival reduced by $69 \%$. A third study, based on a single center, reported that cardiac surgery patients who had complications were more likely to die or have a prolonged length of stay. ${ }^{22}$

In contrast to these other studies, we examined a relatively homogeneous population undergoing only isolated CABG surgery, as opposed to modeling the effect of complications on mortality for several diverse surgical populations using a single model. By including several unrelated procedures within a single regression model, these other studies might not adequately control for preoperative risk factors because it is unlikely that the effect of these risk factors on mortality will be the same across different surgical procedures. For example, it is unlikely that a history of myocardial infarction is associated with the same risk of death in a patient undergoing a carotid endarterectomy compared with a patient undergoing an open abdominal aortic aneurysm repair. ${ }^{23}$

In contrast to Silber and colleagues, ${ }^{7}$ we were unable to quantify the effect of the "first" postoperative complication on outcome because we did not have access to patient charts and the CSRS data set does not date postoperative complications. It is likely that some of the complications included in our analysis might, in some cases, occur "downstream" of the first complication. For example, renal failure could be a first complication when it occurs because of a low cardiac output after terminating cardiopulmonary bypass or it might be a "delayed" complication when it occurs in the setting of multisystem organ failure in a patient with pneumonia and sepsis. However, some of the complications, such as transmural myocardial infarction, stroke, deep sternal wound infection, and bleeding requiring reoperation, are likely to represent first complications as opposed to delayed complications. From the standpoint of quality improvement, it is more useful to measure the effect of first complications on mortality because efforts to prevent complications would be ideally targeted at first complications, as opposed to targeting delayed complications that occur as a result of a first complication. 
Our results should be interpreted with caution, because this study has several important limitations. First, the data on complications might not be completely accurate. Previous audits by the NYS Department of Health have found that complications are undercoded in the CSRS. ${ }^{\S}$ Second, it was necessary to impute the values for ejection fraction in $3 \%$ of the cases. Third, although we believe that our analysis controlled for all potentially relevant confounders, it is possible that the absence of unmeasured variables might have biased our findings. Finally, this study is based on data from NYS and might not be generalizable to other regions of the United States.

\section{Conclusions}

In summary, we find that complications after isolated CABG surgery are associated with a 1.4- to 8-fold increase in the odds of death after adjusting for severity of disease and comorbidities. This information might prove valuable to hospitals in their efforts to design quality improvement initiatives and care protocols to improve mortality after CABG surgery. Further studies are necessary to develop a more comprehensive set of evidence-based guidelines aimed at reducing complication rates for $\mathrm{CABG}$ surgery and to evaluate the benefit of implementing these guidelines once they have been developed.

\section{References}

1. Thom T, Haase N, Rosamond W, Howard VJ, Rumsfeld J, Manolio T, et al. Heart disease and stroke statistics-2006 update: a report from the American Heart Association Statistics Committee and Stroke Statistics Subcommittee. Circulation. 2006;113:e85-151.

2. Hannan EL, Racz MJ, Walford G, Jones RH, Ryan TJ, Bennett E, et al. Long-term outcomes of coronary-artery bypass grafting versus stent implantation. N Engl J Med. 2005;352:2174-83.

3. Hannan EL, Kilburn H, Jr., Racz M, Shields E, Chassin MR. Improving the outcomes of coronary artery bypass surgery in New York State. JAMA. 1994;271:761-6.

4. O'Connor GT, Plume SK, Olmstead EM, Morton JR, Maloney CT, Nugent WC, et al. A regional intervention to improve the hospital mortality associated with coronary artery bypass graft surgery. The Northern New England Cardiovascular Disease Study Group. JAMA. 1996;275:841-6.

5. Hannan EL, Sarrazin MS, Doran DR, Rosenthal GE. Provider profiling and quality improvement efforts in coronary artery bypass graft surgery: the effect on short-term mortality among Medicare beneficiaries. Med Care. 2003;41:1164-72.

6. Khuri SF, Henderson WG, DePalma RG, Mosca C, Healey NA, Kumbhani DJ. Determinants of long-term survival after major surgery

$\S$ Based on personal communication with Dr. Michael Racz, NYS Department of Health (2006). and the adverse effect of postoperative complications. Ann Surg. 2005;242:326-41.

7. Silber JH, Rosenbaum PR, Trudeau ME, Chen W, Zhang X, Kelz RR, et al. Changes in prognosis after the first postoperative complication. Med Care. 2005;43:122-31.

8. Geraci JM, Ashton CM, Kuykendall DH, Johnson ML, Wu L. International Classification Of Diseases, 9th Revision, Clinical Modification codes in discharge abstracts are poor measures of complication occurrence in medical inpatients. Med Care. 1997;35:589-602.

9. Romano PS, Chan BK, Schembri ME, Rainwater JA. Can administrative data be used to compare postoperative complication rates across hospitals? Med Care. 2002;40:856-67.

10. Romano PS, Schembri ME, Rainwater JA. Can administrative data be used to ascertain clinically significant postoperative complications? Am J Med Qual. 2002;17:145-54.

11. Geraci JM. The demise of comparative provider complication rates derived from ICD-9-CM code diagnoses. Med Care. 2002;40:847-50.

12. Lee DS, Donovan L, Austin PC, Gong Y, Liu PP, Rouleau JL, et al. Comparison of coding of heart failure and comorbidities in administrative and clinical data for use in outcomes research. Med Care. 2005;43:182-8.

13. Birman-Deych E, Waterman AD, Yan Y, Nilasena DS, Radford MJ, Gage BF. Accuracy of ICD-9-CM codes for identifying cardiovascular and stroke risk factors. Med Care. 2005;43:480-5.

14. Glance LG, Dick AW, Osler TM, Mukamel DB. Does date stamping ICD-9-CM codes increase the value of clinical information in administrative data? Health Serv Res. 2006;41:231-51.

15. Glance LG, Dick AW, Osler TM, Mukamel DB. Accuracy of hospital report cards based on administrative data. Health Serv Res. 2006;41: 1413-37.

16. Hannan EL, Kilburn H Jr, Bernard H, O’Donnell JF, Lukacik G, Shields EP. Coronary artery bypass surgery: the relationship between inhospital mortality rate and surgical volume after controlling for clinical risk factors. Med Care. 1991;29:1094-107.

17. Little RJA, Rubin DB. Statistical analysis with missing data. 2nd ed. New York: Wiley; 2002.

18. Royston P, Altman DG. Regression using fractional polynomials of continuous covariates: parsimonious parameteric modeling. Appl Stat. 1994;43:429-67.

19. White H. A heteroskedasticity-consistent covariance matrix estimator and a direct test for heteroskedasticity. Econometrica. 1980;48:817-30.

20. Hosmer DW, Lemeshow S. Applied logistic regression. 2nd ed. New York: Wiley-Interscience Publication; 2000.

21. Eagle KA, Guyton RA, Davidoff R, Edwards FH, Ewy GA, Gardner TJ, et al. ACC/AHA 2004 guideline update for coronary artery bypass graft surgery: a report of the American College of Cardiology/ American Heart Association Task Force on Practice Guidelines (Committee to Update the 1999 Guidelines for Coronary Artery Bypass Graft Surgery). Circulation. 2004;110:e340-437.

22. Welsby IJ, Bennett-Guerrero E, Atwell D, White WD, Newman MF, Smith PK, et al. The association of complication type with mortality and prolonged stay after cardiac surgery with cardiopulmonary bypass. Anesth Analg. 2002;94:1072-8.

23. Eagle KA, Berger PB, Calkins H, Chaitman BR, Ewy GA, Fleischmann KE, et al. ACC/AHA guideline update for perioperative cardiovascular evaluation for noncardiac surgery-executive summary a report of the American College of Cardiology/American Heart Association Task Force on Practice Guidelines (Committee to Update the 1996 Guidelines on Perioperative Cardiovascular Evaluation for Noncardiac Surgery). Circulation. 2002;105:1257-67. 
Appendix 1. Full model

\begin{tabular}{|c|c|c|}
\hline & $\begin{array}{l}\text { Odds } \\
\text { ratio }\end{array}$ & $\begin{array}{c}P \\
\text { value }\end{array}$ \\
\hline \multicolumn{3}{|l|}{ Preoperative risk factors } \\
\hline \multicolumn{3}{|l|}{ Demographics } \\
\hline Age & 1.09 & $<.001$ \\
\hline Female sex & 1.40 & $<.001$ \\
\hline $\mathrm{BSA}^{2}$ & 0.128 & $<.001$ \\
\hline $\mathrm{BSA}^{2} \ln (\mathrm{BSA})$ & 5.25 & $<.001$ \\
\hline \multicolumn{3}{|l|}{ Hemodynamic status } \\
\hline Unstable & 1.47 & .041 \\
\hline Shock & 3.25 & $<.001$ \\
\hline CPR & 4.34 & $<.001$ \\
\hline Intravenous nitroglycerin within $24 \mathrm{~h}$ & 1.34 & $<.001$ \\
\hline CHF, this admission & 1.22 & .028 \\
\hline CHF, previous admission & 1.32 & .003 \\
\hline Malignant ventricular arrhythmia & 1.52 & .009 \\
\hline Emergency transfer to $\mathrm{OR}$ after $\mathrm{PCl}$ & 1.19 & .532 \\
\hline \multicolumn{3}{|l|}{ Comorbidities } \\
\hline Diabetes & 1.26 & .002 \\
\hline Hepatic failure & 2.36 & .141 \\
\hline Renal failure, not on dialysis & 1.12 & .556 \\
\hline Renal failure, on dialysis & 4.32 & $<.001$ \\
\hline Chronic obstructive pulmonary disease & 1.31 & .002 \\
\hline \multicolumn{3}{|l|}{ Severity of atherosclerotic disease } \\
\hline Previous stroke & 1.20 & .092 \\
\hline Carotid disease & 1.21 & .011 \\
\hline Aortoiliac disease & 1.70 & $<.001$ \\
\hline Femoral-popliteal disease & 1.17 & .093 \\
\hline Calcified aorta & 1.42 & .001 \\
\hline \multicolumn{3}{|l|}{ Ventricular function } \\
\hline Ejection fraction & 0.980 & $<.001$ \\
\hline Previous $\mathrm{Ml},<6 \mathrm{~h}$ & 2.25 & .001 \\
\hline Previous MI, 6-23 h & 1.12 & .691 \\
\hline Previous MI, 1-7 d & 1.45 & .001 \\
\hline Previous $\mathrm{Ml},>7 \mathrm{~d}$ & 1.22 & .023 \\
\hline \multicolumn{3}{|l|}{ Previous cardiac surgery } \\
\hline 1 & 2.32 & $<.001$ \\
\hline$\geq 2$ & 4.51 & $<.001$ \\
\hline \multicolumn{3}{|l|}{ Extent of coronary artery disease } \\
\hline Left main, $70 \%-89 \%$ & 1.20 & .075 \\
\hline Left main, >89\% & 1.40 & .007 \\
\hline \multicolumn{3}{|l|}{ Postoperative complications } \\
\hline Transmural myocardial infarction & 7.90 & $<.001$ \\
\hline Respiratory failure & 6.02 & $<.001$ \\
\hline Renal failure, dialysis & 7.15 & $<.001$ \\
\hline Stroke, within $24 \mathrm{~h}$ & 4.09 & $<.001$ \\
\hline Stroke, $>24 \mathrm{~h}$ & 3.58 & $<.001$ \\
\hline Bleeding requiring reoperation & 2.60 & $<.001$ \\
\hline Gastrointestinal bleeding & 3.49 & $<.001$ \\
\hline Deep sternal wound infection & 1.39 & .126 \\
\hline Sepsis & 2.74 & $<.001$ \\
\hline
\end{tabular}

C-statistic $=0.917 . O R$, Odds ratio; $B S A$, body surface area; $C P R$, cardiopulmonary resuscitation; $C H F$, congestive heart failure; $O R$, operating room; $\mathrm{PCl}$, percutaneous coronary intervention; $\mathrm{MI}$, myocardial infarction. 